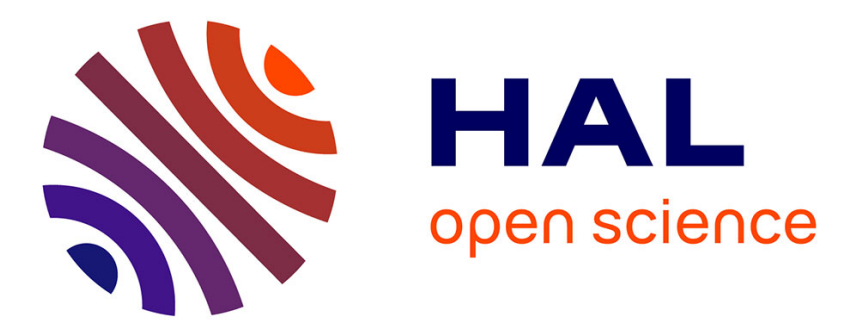

\title{
Neurocognitive impairment is associated with erectile dysfunction in cirrhotic patients
}

Sara Philonenko, Pauline Rivière, Maxime Mallet, Florian Poullenot, Simona

Tripon, Mona Munteanu, Ryad Boukherrouf, Philippe Sultanik, Morgan

Roupret, Dominique Thabut, et al.

\section{To cite this version:}

Sara Philonenko, Pauline Rivière, Maxime Mallet, Florian Poullenot, Simona Tripon, et al.. Neurocognitive impairment is associated with erectile dysfunction in cirrhotic patients. Digestive and Liver Disease, 2019, 51, pp.850 - 855. 10.1016/j.dld.2019.03.030 . hal-03484485

\section{HAL Id: hal-03484485 \\ https://hal.science/hal-03484485}

Submitted on 20 Dec 2021

HAL is a multi-disciplinary open access archive for the deposit and dissemination of scientific research documents, whether they are published or not. The documents may come from teaching and research institutions in France or abroad, or from public or private research centers.
L'archive ouverte pluridisciplinaire HAL, est destinée au dépôt et à la diffusion de documents scientifiques de niveau recherche, publiés ou non, émanant des établissements d'enseignement et de recherche français ou étrangers, des laboratoires publics ou privés.

\section{(ㅇ)(1) $\$$}

Distributed under a Creative Commons Attribution - NonCommerciall 4.0 International 
Neurocognitive impairment is associated with erectile dysfunction in cirrhotic patients

Running title: Erectile dysfunction in cirrhosis

Sara Philonenko (1, 2), Pauline Rivière (3), Maxime Mallet (1, 2), Florian Poullenot (3), Simona Tripon (1, 2), Mona Munteanu (4), Ryad Boukherrouf (1, 2), Philippe Sultanik (1, 2), Morgan Roupret (2, 5), Dominique Thabut (1, 2), Marika Rudler (1, 2)

1: Service d'Hépato-Gastroentérologie, Groupe Hospitalier Pitié-Salpêtrière Charles Foix, Paris, France.

2: Sorbonnes Universités, UPMC, Paris, France

3: Service d'Hépato-Gastroentérologie, Centre Hospitalier Universitaire de Bordeaux, France 4: Biopredictive, Paris, France

5: Service d'urologie, Groupe Hospitalier Pitié-Salpêtrière Charles Foix, Assistance PubliqueHôpitaux de Paris, Paris, France, UPMC

\section{Corresponding author:}

Dr Marika RUDLER

Unité de Soins Intensifs d'Hépatologie

Groupe Hospitalier Pitié-Salpêtrière Charles Foix

Tel.: 33 (0)1.42.16.14.54

Fax: +33(0)1.42.16. 10.08

Mail: marika.rudler@aphp.fr 
Electronic word count: 3022

Number of figures: 3

Number of tables: 3

Number of supplementary Figure: 1

Number of supplementary tables: 3

Abbreviations (alphabetical order)

Critical flicker frequency: CFF

Digital symbol test: DST

Erectile dysfunction: ED

Follicle-stimulating hormone: FSH

International Index of Erectile Function questionnaire: IIEF5 questionnaire

Hepatic encephalopathy: HE

International normalized ratio: INR

Liver transplantation: LT

International prostate symptom score: IPSS

Minimal hepatic encephalopathy: MHE

Model for End-stage Liver Disease: MELD

Line tracing test: LTT

Luteinising hormone: $\mathrm{LH}$

Non-alcoholic steato-hepatitis: NASH

Number connecting test A: NCT-A

Number connecting test B: NCT-B

Psychometric hepatic encephalopathy test score: PHES

Serial dotting test: SDT

Transjugular intrahepatic portosystemic shunt: TIPS

Conflict of interest: None

Financial support: None

Authors' contributions:

Sara Philonenko: Study design, patient management, data collection, and drafting of the 
manuscript

Pauline Rivière: data collection, critical review of the manuscript

Maxime Mallet: Patient management and critical review of the manuscript

Forian Poullenot: data collection, critical review of the manuscript

Simona Tripon: Patient management and critical review of the manuscript

Mona Munteanu: Statistical analysis and critical review of the manuscript

Ryad Boukherrouf: Data collection

Philippe Sultanik: Patient management

Morgan Roupret: Study design and critical review of the manuscript

Dominique Thabut: Study design and critical review of the manuscript

Marika Rudler: Study design, patient management, data collection, and drafting of the manuscript 


\begin{abstract}
Introduction: Erectile dysfunction (ED) is common in patients with chronic diseases. It is evaluated using the International Index of Erectile Function (IIEF5) questionnaire. The relationship between ED and cirrhosis is complex. The aims of our study were (1) to assess the prevalence of ED in cirrhosis and (2) to evaluate factors associated with ED, with a special focus on minimal hepatic encephalopathy (MHE).

Methods: We performed a prospective, observational study. Patients with cirrhosis were invited to complete the IIEF5 questionnaire. The exclusion criteria were clinical hepatic encephalopathy (HE) and dementia. MHE was evaluated by the psychometric hepatic encephalopathy test score (PHES) and the critical flicker frequency (CFF).

Results: Between April 2016 and April 2017, 87 patients were included (age: 55 [51-57] years, Child-Pugh score: 8 [7-9], MELD score: 13 [11-16]. Minimal HE was diagnosed in $33 \%$ of the patients according to the PHES and in $44 \%$ of the patients according to the CFF. ED was diagnosed in $74 / 87$ patients (85\%) when compared to $12.5 \%$ in healthy controls $(\mathrm{p}<0.001)$. In a multivariate analysis, the independent factors associated with ED were age, Child-Pugh and MELD scores. Significant correlations were identified between the IIEF5 and each component of the PHES.
\end{abstract}

Conclusion: ED should be systematically screened in cirrhotics, especially in patients with MHE. 
Introduction

Erectile dysfunction (ED) is defined as the inability to develop or maintain an erection during sexual intercourse $(1,2)$ and is the main concern in terms of sexual dysfunction among men. The prevalence of ED increases with age, ranging from $9.1 \%$ in men $40-49$ years to $54.9 \%$ in men >70 years (3). The major risk factors for ED are as follows: diabetes; heart conditions; tobacco use; obesity; injuries to the nerves that control erection; medications such as antidepressants; psychological conditions such as stress, anxiety, or depression; and drug or alcohol use (4). The International Index of Erectile Function (IIEF5) is a simple and wellvalidated tool for the evaluation of ED (5) and is considered the gold standard for the diagnosis and evaluation of symptom severity. The link between liver disease, especially cirrhosis, and ED has not been established. Many studies have reported that several conditions responsible for chronic liver disease are associated with an increased prevalence of ED; chronic hepatitis $\mathrm{C}(6,7)$ or $\mathrm{B}(7,8)$, for example, have been shown to be associated with sexual impairment. Moreover, alcohol consumption is a clear risk factor for ED (9). More recently, a study suggested that non-alcoholic steatohepatitis (NASH) could be associated with ED (10). Chronic liver disease, especially cirrhosis, may also be associated with an increased risk of ED $(11,12)$. Hormonal abnormalities, such as hyperoestrogenism, are a well-known consequence of liver failure. Data regarding the prevalence of ED are inhomogeneous, with reports varying from $63 \%$ (12) to $93 \%(13,14)$ in patients who are candidates for liver transplantation (LT). The largest study published to date (12) showed that ED in cirrhotic patients is impacted by liver function, portal hypertension and known risk factors, such as diabetes mellitus and arterial hypertension. Nevertheless, a more recent study including 102 patients with Child-Pugh A cirrhosis suggested that cirrhosis per se was not a risk factor for ED (15). In summary, data are inhomogeneous regarding the link between ED and chronic live disease. Moreover, difficulties in the diagnosis of ED in cirrhotic patients involve many emotional aspects related to the patient as well as a lack of experience among hepatologists regarding this condition. Lastly, cirrhosis is a life-threatening disease, and sexual activity may be considered a minor issue in this particular population.

Hepatic encephalopathy (HE) is an important complication of cirrhosis and is characterised by neurological or neuropsychological symptoms caused by liver disease (16). Minimal HE (MHE) produces subtle manifestations that can only be diagnosed through neurocognitive tests, as clinical evaluations are typically normal for most patients (17). MHE causes poor quality of life (18), is associated with adverse events such as falls (19) and is a major risk 
factor for motor vehicle accidents. MHE may also be responsible for subtle modifications in behaviour or anxiety (20). Nevertheless, the link between MHE and ED has never been studied. Therefore, in this study, we aimed (1) to evaluate the prevalence of ED in a population of patients with cirrhosis of various aetiologies and (2) to describe the risk factors associated with the higher prevalence of ED in this population, with a special focus on MHE. 


\section{Patients and methods}

This prospective observational study was performed at La Pitié-Salpêtrière University Hospital, which is a tertiary care centre in Paris, France. Written consent for study participation was obtained from all patients after detailed information about the study was provided in accordance with the Declaration of Helsinki.

\section{Patients}

Inclusion and exclusion criteria

All patients referred to our Hepatology Unit were prospectively screened between April 2016 and April 2017. The inclusion criteria were male gender and a diagnosis of cirrhosis (based on clinical, biological, and/or radiological parameters). The exclusion criteria were the presence of clinical HE and dementia. Healthy controls (HC) were consecutively recruited from September to November 2015 from the preventive medicine unit of a National company (EDF-GRDF; Lille, France), as previously described (21).

\section{Study design \\ Clinical evaluation}

Clinical examinations were performed on the day of study enrolment. Liver function was assessed using the Child-Pugh score and the Model for End-stage Liver Disease (MELD) score. Previous portal hypertension-related complications were recorded, including HE, variceal bleeding, hepatocellular carcinoma, and ascites. Body mass index (BMI) was evaluated after paracentesis in patients with ascites. Concomitant diseases were also recorded, including hypertension, diabetes mellitus, hyperlipidaemia, metabolic syndrome, and previous history of ED. All medications were recorded, with specific attention paid to beta-blockers, diuretics, and benzodiazepines. Alcohol and tobacco use were evaluated.

\section{IIEF5 questionnaire}

The patients were invited to complete the IIEF5 questionnaire (5) (Supplementary Table 1). Briefly, 5 items were scored from 1 to 5 points for a minimum score of 5 and a maximum score of 25. ED was classified into the following categories: 5-10: severe ED; 11-15: mild ED; 16-20: moderate DE; and 21-25: no ED. 
The IPSS (22) (Supplementary Table 2) is based on responses to seven questions concerning urinary symptoms and one question concerning quality of life. Each answer is assigned 0 to 5 points, for a total score ranging from 0 to 25 (asymptomatic to very symptomatic). Quality of life with respect to urinary symptoms is evaluated by the following question: "If you were to spend the rest of your life with your urinary condition just the way it is now, how would you feel about that?" The answer is scored from 0 (delighted) to 6 (terrible). Good quality of life is defined as a score of 0,1 , or 2 .

\section{Evaluation of MHE}

The psychometric HE test score (PHES) was used to evaluate possible neuropsychological abnormalities. Briefly, the PHES is based on 5 tests: the digit symbol test (DST), the number connection test (NCT) parts A and B, the serial dot test (SDT), and the line tracing test (LTT). The results were corrected for age and educational level and were analysed according to Spanish standards (http://www.redeh.org/phesapp/datosE.html). MHE was defined by a PHES equal to or less than -4 , as previously described (23).

The critical flicker frequency (CFF) was assessed on the same day as the PHES. A mean of 10 measurements was calculated after training procedures were conducted. MHE was defined by a score $>39 \mathrm{~Hz}(24)$.

\section{Laboratory analysis}

Peripheral blood was collected on the same day as the PHES and CFF assessments for routine blood tests and determination of liver function. Hormone analysis was performed and included testosterone, follicle-stimulating hormone (FSH), and luteinising hormone (LH).

\section{Definitions}

Clinical HE was defined as a West Haven score $>1$. MHE was defined by either a PHES equal to or less than -4 or a CFF value of less than $39 \mathrm{~Hz}$, as previously described (24). Metabolic syndrome was defined by the presence of 3 of 5 items (25).

\section{Statistical analysis}

Comparison of patients and HC for categorical data was done through an age-adjusted Cochran-Mantel-Haenszel Chi-square test (26). The groups were stratified in 6 age strata by a sub-classification matching algorithm (27). Continuous variables are reported as medians and 
interquartile range (IQR), and categorical variables are reported as numbers (n) and percentages. A Student's t test was used for comparisons of normally distributed data, and the Mann-Whitney U test was used to compare data without a normal distribution in patients with or without ED. Pearson's chi-square test or Fisher's exact test were used for group comparisons between patients with and without ED. Multivariate binary logistic regression models were used to determine the independent factors associated with the presence of ED. Univariate analysis was performed first, and then all significant variables were entered into a multivariate model. NCSS statistical software (Kaysville, Utah USA) was used for all statistical analyses. 


\section{Results}

\section{Baseline characteristics of patients and controls}

One hundred five patients were invited to participate in the study; 18 refused to participate. Eighty-seven patients were included in the final analysis (Figure 1). The median age was 60 years, the median Child-Pugh score was 8, the median MELD score was 13, and the cause of cirrhosis was alcohol, virus, NASH, mixed, and other in 33, 16, 8, 24, and 6 patients, respectively. Alcohol abstinence was 74\% amongst patients with alcohol-related cirrhosis and $100 \%$ in non-alcoholic cirrhosis. No patients were treated for portopulmonary hypertension. Regarding the comparative group, 56 men of median age 36 were recruited in preventive medicine. After age-adjustment, when patients were compared to controls for known risks factors for ED in the general population, no difference was found between the 2 groups for diabetes, or arterial hypertension. A significant difference was observed regarding betablockers use and nicotine abuse (supplementary Table 3).

\section{Prevalence of ED}

Overall, ED was significantly more frequent in patients $(74 / 87,85 \%)$ than in $\mathrm{HC}(7 / 56$, $12.5 \%)$, when compared as age-matched pairs ( $\mathrm{p}<0.001)$. ED was severe in 34 patients $(39 \%)$, mild in 16 patients (18\%), and moderate in 24 patients $(28 \%)$. The main clinical and biological characteristics according to the presence of ED are detailed in Table 1. MELD score and Child-Pugh score were significantly higher in patients with ED.

\section{ED and MHE (Table 2)}

Thirty-five patients had a history of clinical HE, and all were treated with lactulose and/or rifaximin. CFFs were available for 64/87 patients and PHESs were available for 76/87 patients. MHE was diagnosed in 25 patients (33\%) according to the PHES and in 28 patients (44\%) according to the CFF. PHESs were significantly worse in patients with ED. All components of the PHES, except for the SDT, were significantly different between the patients with and without ED (Figure 2). The CFF was lower in patients with ED, although the difference was not significant. In the subgroup of patients with Child-Pugh A cirrhosis $(n=25)$, ED was significantly more frequent in patients with MHE (100\% vs 43\%, p=0.01). A correlation was found between the PHES and the IIEF5 score $(r=0.2459, p=0.03)$ (Supplementary Figure 1). 


\section{Factors associated with ED}

In the univariate analysis, the factors associated with ED were age, MELD score, Child-Pugh score, FibroTest, low bioavailable testosterone level, NCT-A, NCT-B, DST, and LTT scores, and total PHES. In the multivariate analysis using 2 different models, the independent factors that remained associated with ED were the Child-Pugh score (OR=3.05, CI 95\% [1.39-6.7], $\mathrm{p}=0.005)$, MELD score $(\mathrm{OR}=1.19$, CI 95\% [1.01-1.40], $\mathrm{p}=0.04)$, and age (OR=1.27, CI 95\% [1.09-1.5], p=0.002) (Table 3, model 1 and 2). Negative correlations were identified between the IIEF5 score and the IPSS ( $\mathrm{r}=-0.2972, \mathrm{p}=0.03$ ) and between the IIEF5 score and the IPSS quality of life score $(\mathrm{r}=-0.3239, \mathrm{p}=0.002)$ (Figure 3). Negative correlations were also found between the IIEF5 score and the NCT-A score $(r=-0.0899, p=0.0045)$, NCT-B score ( $r=-$ 0.0020, $\mathrm{p}=0.003)$, SDT score $(\mathrm{r}=-0.0447, \mathrm{p}=0.04)$, and LTT score $(\mathrm{r}=-0.0212, \mathrm{p}=0.04)$. A positive correlation was found between the IIEF5 score and the DST score $(r=0.2274$, $\mathrm{p}=0.001$ ) 


\section{Discussion}

In this study, we confirmed that the prevalence of ED was high in cirrhotic patients; it was higher than recently described (12), as $85 \%$ of our population was diagnosed with ED, and significantly higher than in our series of HC. We also established that the severity of liver disease, as evaluated by the MELD or Child-Pugh score, and age were an-independent factors associated with ED. Moreover, we found a very streng correlation between neurocognitive performance evaluated by the PHES and ED. Lastly, the IPSS and quality of life were both correlated with ED, suggesting that a link may exist between prostatic pathology and ED in cirrhosis patients. To our knowledge, the results regarding MHE and prostatic pathology have not been described previously.

Last year, 2 studies were published regarding the prevalence of DE in cirrhosis: Paternostro and colleagues (12) found a lower prevalence of DE in cirrhosis (63\%) than we did; however, the difference can be explained by the older age of our cohort. The second one (15) did not describe any difference in terms of prevalence of DE (55.9\%) in cirrhosis than in the general population. Nevertheless, this study was conducted in a cohort of Child-Pugh A cirrhosis and did not include any control group of healthy subjects. A much higher prevalence was found in our study: this result may be related to the severity of cirrhosis, as about $1 / 3$ of our patients had Child-Pugh C cirrhosis.

Although the prevalence of ED was high in the present cohort, we were surprised that only 4 patients (4\%) had consulted an urologist for ED management before our study. This incredibly low rate suggests that this condition is not always assessed by the attending hepatologist and that patients do not readily discuss ED during medical consultations. To determine whether liver failure or portal hypertension can cause ED, an evaluation of the evolution of ED after LT in a large cohort of patients would be required. Two studies conducted in China $(13,14)$ have shown slight improvements in erectile function after LT. However, the results were obtained from a small cohort of patients, and the authors insisted on an association between post-LT ED and immunosuppressive therapy, which is an obvious confounding factor. Some of our patients were candidates for LT, and we plan to evaluate these patients again at 1 year after LT. Pathophysiology of ED remains indeed debated in cirrhosis, although modified hormonal profile has been extensively described, such as a reduction of serum levels of testosterone. Nonetheless, testosterone level was not found to be an independent factor associated with ED in the present study in multivariate analysis. This result was not surprising, as circulating androgens progressively decrease with the severity of liver disease (28), suggesting that liver function and testosterone levels are not independent. 
Interestingly, we found that patients with abnormal neurocognitive test results had a significantly higher prevalence of ED, which has not been reported previously and may warrant further exploration. Nevertheless, in multivariate analysis, only 2 independent factors were associated with ED: age and liver failure, and MHE was not. Age is a well-described factor of ED (3). This result is therefore in complete agreement with previous published data in general population. As previously shown in Paternostro's study, severity of liver failure is a risk factor for ED. It is well recognized that hyperestrogenism and a reduction of testosterone levels are associated with advanced liver disease (28). Thus, the role of neurocognitive impairment in ED remains unclear: interestingly we found that in the subgroup of patients with Child-Pugh A cirrhosis, 100\% of patients with MHE had ED. Moreover, there was a good correlation between PHES and IIEF5 score $(r=0.2459, \mathrm{p}=0.03)$. This finding suggests that MHE might be an additional risk factor for ED and that ED should be sereened systematically in patients with MHE. Our study did not allow us to conclude that MHE may be a clear risk factor for ED. whether MHE is respensible for decreased sexual desire. Notably, decreased libido is not included in the definition of ED. Lastly, resolution of MHE could potentially improve ED, and treatment for MHE could be part of the treatment for ED. Noteworthy, we included patients treated with psychoactive drugs such as benzodiazepines, or active drinkers. These 2 situations may have created a bias in the interpretation of neurocognitive tests. Nevertheless, we voluntarily chose not to exclude this subgroup of patients, in order to reflect a real life cohort of patients.

Regarding the medical management of ED in cirrhosis patients, a randomized controlled trial on the effect of vardenafil is currently recruiting participants. The efficacy of vardenafil or sildenafil ranges from 50 to $80 \%$ in the general population, but data are lacking for cirrhotic patients. Tolerance must be evaluated because peripheral vasodilation is common in end-stage cirrhosis.

Our study has several limitations. As previously stated, $85 \%$ of the patients were diagnosed with ED, reflecting a substantially higher prevalence than the rate of $10-20 \%$ reported for the general population of the same age. Cirrhosis appears to be strongly associated with ED. Therefore, our 2 groups of patients were not equally balanced in terms of effects, and only 13 patients were not diagnosed with ED, which is probably why we could not identify classic risk factors for ED such as diabetes mellitus, hypertension, or tobacco use. Moreover, we used the PHES for the diagnosis of MHE. The results were corrected for age and educational level and were analysed according to Spanish standards, as these tests have not been validated in French language. Even if prospective, our study may have selection bias: 18 patients refused 
to answer the questionnaire. Most of them did not give any explanation but one could imagine that those patients may have refused due to sexual inactivity or severe ED. Moreover, we voluntarily excluded patients with clinical HE as we believed that these patients may not be able to file correctly the questionnaire. Lastly, we did not conduct psychiatric evaluations or administer quality of life questionnaires to evaluate the relationship between ED and psychiatric disorders or the impact of ED on quality of life.

In conclusion, the prevalence of ED was very high in our cohort of patients with cirrhosis. Therefore, ED should be systematically screened in this population. We hypothesize that ED may be related to liver failure, and prostatic pathology. MHE may also play a role. To address this, the prevalence of ED should be investigated before and after LT in the same population, with a focus on changes in neurocognitive test results and hormonal profiles and consideration of immunosuppressive therapy as a potential confounding factor. Further studies are warranted. 


\section{References}

1: NIH Consensus Development Panel on Impotence. NIH Consensus Conference: impotence. JAMA 1993;270:83-90.

2: Lue TF. Erectile dysfunction. N Engl J Med. 2000;342(24):1802- 1813.

3: Laumann EO, West S, Glasser D, Carson C, Rosen R, Kang JH. Prevalence and correlates of erectile dysfunction by race and ethnicity among men aged 40 or older in the United States: from the male attitudes regarding sexual health survey. J Sex Med. 2007;4(1):57-65. 32.

4: Feldman HA, Goldstein I, Hatzichristou DG, Krane BJ, Mckinlay JB. Impotence and its medical and psychosocial correlates: results of the Massachusetts Male Aging Study. J Urol 1994; 151:54-61.

5: Rosen RC, Riley A, Wagner G, Osterloh IH, Kirkpatrick J, Mishra A. The international index of erectile dysfunction (IIEF): a multidimensional scale for assessment of erectile dysfunction. J Urol 1997;49:822-30.

6: Vergniol J, Duc S, Hou G, Hiriart JB, Foucher J, Chenus F, Fabères C, Chermak F, Lafournière A, Souakri N, de Lédinghen V. Sexual quality of life is impaired in patients with chronic hepatitis C. Int J Impot Res. 2016;28(2):68-73.

7: Chung SD, Keller JJ, Liang YC, Lin HC. Association between viral hepatitis and erectile dysfunction: a population-based case-control analysis. J Sex Med. 2012;9(5):1295-302.

8: Kim M, Kim SY, Rou WS, Hwang SW, Lee BS. Erectile dysfunction in patients with liver disease related to chronic hepatitis B. Clin Mol Hepatol. 2015;21(4):352-7.

9: Zhang X, Yang B, Li N, Li H. Prevalence and Risk Factors for Erectile Dysfunction in Chinese Adult Males. J Sex Med 2017 14(10):1201-1208. 
10: Duman DG, Biçakci E, Çelikel ÇA, Akbal. C. Nonalcoholic Fatty Liver Disease is Associated with Erectile Dysfunction: A Prospective Pilot Study. J Sex Med. 2016 Mar;13(3):383-8.

11: Huyghe E, Kamar N, Wagner F, Capietto AH, El-Kahwaji L, Muscari F, Plante P, Rostaing L. Erectile dysfunction in end-stage liver disease men. J Sex Med. 2009;6(5):1395401.

12: Paternostro R, Heinisch BB, Reiberger T, Mandorfer M, Schwarzer R, Seeland B, Trauner M, Peck-Radosavljevic M, Ferlitsch A. Erectile dysfunction in cirrhosis is impacted by liver dysfunction, portal hypertension, diabetes and arterial hypertension. Liver Int. 2018 Jan 24. doi: 10.1111/liv.13704.

13: Wang G, Yang J, Li M, Liu B, Jiang N, Fu B, Jin H, Yang Y, Chen G. Liver transplantation may improve ercetile function in patients with benign end-stage liver disease: single-center chinese experience. Exp Clin Transp 2013; 4: 332-338.

14: Chien Y, Chiang H, Lin P, Chen Y. Erectile function in men with end-stage liver disease improves after living donor liver transplantation. BMC urology 2015; 15:83.

15: Maimone S, Saffioti F, Oliva G, Di Benedetto A, Alibrandi A, Filomia R(2), Caccamo G, Saitta C, Cacciola I, Pitrone C, Squadrito G, Raimondo G. Erectile dysfunction in compensated liver cirrhosis. Dig Liver Dis. 2018 Oct 29. pii: S1590-8658(18)31211-8. doi: 10.1016/j.dld.2018.10.015.

16: Vilstrup et al. "Hepatic encephalopathy in chronic liver disease: 2014 Practice Guideline by the American Association for the Study of Liver Diseases and the European Association for the Study of the Liver" Hepatology 2014.

17: Groeneweg M, Moerland W, Quero JC, Krabbe PF, Schalm SW. Screening of subclinical hepatic encephalopathy. J Hepatol 2000;32: 748-753.

18: Schomerus H, Hamster W. Quality of life in cirrhotics with minimal hepatic encephalopathy. Metab Brain Dis 2001;16:37-41. 
19: Román E, Córdoba J, Torrens M, Torras X, Villanueva C, Vargas V, Guarner C, Soriano G. Minimal hepatic encephalopathy is associated with falls. Am J Gastroenterol. 2011;106 (3):476-82.

20: Nardelli S, Pentassuglio I, Pasquale C, Ridola L, Moscucci F, Merli M, Mina C, Marianetti M, Fratino M, Izzo C, Merkel C, Riggio O. Depression, anxiety and alexithymia symptoms are major determinants of health related quality of life (HRQoL) in cirrhotic patients. Metab Brain Dis. 2013 Jun;28(2):239-43. doi: 10.1007/s11011-012-9364-0.

21: Rivière P, Zallot C, Desobry P, Sabaté JM, Vergniol J, Zerbib F, Peyrin-Biroulet L, Laharie D, Poullenot F. Frequency of and Factors Associated With Sexual Dysfunction in Patients With Inflammatory Bowel Disease. J Crohns Colitis. 2017 Oct 27;11(11):1347-1352.

22: Barry MJ, Fowler FJ Jr, O'Leary MP, Bruskewitz RC, Holtgrewe HL, Mebust WK, Cockett AT. The American Urological Association symptom index for benign prostatic hyperplasia. The Measurement Committee of the American Urological Association. J Urol. 1992 Nov;148(5):1549-57; discussion 1564.

23: Duarte-Rojo A, Estradas J, Hernández-Ramos R, Ponce-de-León S, Córdoba J, Torre A. Validation of the psychometric hepatic encephalopathy score (PHES) for identifying patients with minimal hepatic encephalopathy. Dig Dis Sci. 2011 ;56(10):3014-23.

24: Kircheis G, Wettstein M, Timmermann L, Schnitzler A, Häussinger D. Critical flicker frequency for quantification of low-grade hepatic encephalopathy. Hepatology. 2002;35(2):357-66.

25: Alberti KG, Zimmet P, Shaw J ; IDF Epidemiology Task Force Consensus Group. The metabolic syndrome- a new worldwide definition. Lancet $2005 ; 366: 1059-62$.

26 : Agresti A. A Survey of Exact Inference for Contingency Tables. Stat Sci. 1992;7(1):13153.

27: Ho ED, Imai K, King G, Stuart EA. MatchIt: Nonparametric Preprocessing for Parametric Causal Inference. Journal of Statistical Software. 2011; 42 (8):1-28. 
28 : Sinclair M, Gow PJ, Angus PW, et al. High circulating oestrone and low testosterone correlate with adverse clinical outcomes in men with advanced liver disease. Liver Int 2016;36:1619-27. 
Table 1: Clinical and biological characteristics of the 87 patients included in the study according to the presence of ED

\begin{tabular}{|c|c|c|c|c|}
\hline Characteristics & Overall $n=87$ & ED $(n=74)$ & No $\operatorname{ED}(n=13)$ & $\mathbf{p}$ \\
\hline Age & 55 [51-57] & $61[58-62]$ & $55[46-62]$ & 0.01 \\
\hline MELD score & $13[11-16]$ & $13[12-16]$ & 8 [7-19] & 0.02 \\
\hline Child-Pugh score & 8 [7-9] & 8 [8-9] & $5[5-8]$ & $<0.001$ \\
\hline $\begin{array}{l}\text { Child-Pugh class } \\
\text { A } \\
\text { B } \\
\text { C }\end{array}$ & $\begin{array}{l}25(29 \%) \\
38(44 \%) \\
24(27 \%)\end{array}$ & $\begin{array}{l}16(22 \%) \\
35(47 \%) \\
23(31 \%)\end{array}$ & $\begin{array}{l}9(70 \%) \\
3(23 \%) \\
1(7 \%)\end{array}$ & 0.002 \\
\hline FibroTest* & $0.89[0.79-0.93]$ & $0.90[0.8-0.95]$ & $0.71[0.68-0.9]$ & 0.02 \\
\hline $\begin{array}{l}\text { Past history of portal hypertension-related } \\
\text { complications }\end{array}$ & $69(79 \%)$ & $61(82 \%)$ & $8(69 \%)$ & 0.13 \\
\hline Past history of $\mathrm{HE}$ & $35(40 \%)$ & $33(45 \%)$ & $2(\&(\%)$ & 0.06 \\
\hline Past history of ascites & $57(65 \%)$ & $52(70 \%)$ & $5(38 \%)$ & 0.05 \\
\hline TIPS & $18(21 \%)$ & $17(23 \%)$ & $1(8 \%)$ & 0.29 \\
\hline Ascites & $47(54 \%)$ & $43(58 \%)$ & $4(31 \%)$ & 0.07 \\
\hline Presence of large oesophageal varices & $64(74 \%)$ & $56(76 \%)$ & $8(61 \%)$ & 0.31 \\
\hline $\begin{array}{l}\text { Cause of cirrhosis } \\
\text { Alcohol/virus/NASH/mixed/other }\end{array}$ & $33 / 16 / 8 / 24 / 6$ & $30 / 15 / 4 / 20 / 5$ & $3 / 1 / 4 / 4 / 1$ & 0.10 \\
\hline Hypertension & $35(40 \%)$ & $25(34 \%)$ & $7(54 \%)$ & 0.35 \\
\hline Diabetes & $34(39 \%)$ & $26(35 \%)$ & $4(31 \%)$ & 0.76 \\
\hline HBA1C & $5.2[5-5.6]$ & $5.1[4.8-5.4]$ & $5.6[5-7.4]$ & 0.22 \\
\hline Dysmetabolic syndrome & $36(41 \%)$ & $27(36 \%)$ & $6(46 \%)$ & 0.69 \\
\hline $\begin{array}{l}\text { Tobacco use } \\
\text { Active smoker } \\
\text { Previous or active smoker }\end{array}$ & $\begin{array}{l}41(47 \%) \\
76(87 \%)\end{array}$ & $\begin{array}{l}32(43 \%) \\
60(81 \%)\end{array}$ & $\begin{array}{l}9(69 \%) \\
11(85 \%)\end{array}$ & $\begin{array}{l}0.08 \\
0.76\end{array}$ \\
\hline Overweight & $30(34 \%)$ & $25(34 \%)$ & $5(38 \%)$ & 0.68 \\
\hline NASH & $24(28 \%)$ & $19(26 \%)$ & $5(38 \%)$ & 0.34 \\
\hline BMI & $25[24-26]$ & $24.2[23.6-26]$ & $26.4[24-36]$ & 0.28 \\
\hline INR & $1.4[1.3-1.5]$ & $1.4[1.3-1.5]$ & $1.2[1-1.8]$ & 0.02 \\
\hline PT & $61[57-65]$ & $60[56-64]$ & 83 [45-96] & 0.01 \\
\hline Platelet count & 113 [102-133] & $112[102-132]$ & $145[91-182]$ & 0.49 \\
\hline Albumin & $30[27-31]$ & $29[26-31]$ & $39[26-45]$ & $<0.001$ \\
\hline Creatinine & $74[67-77]$ & $71[64-76]$ & 77 [67-98] & 0.36 \\
\hline Bilirubin & $26[21-35]$ & $29[24-41]$ & $12[9-26]$ & 0.002 \\
\hline Sodium concentration & 138 [137-139] & 137 [137-139] & $140[137-142]$ & 0.06 \\
\hline Bioavailable testosterone & $0.64[0.5-0.8]$ & $0.55[0.47-0.73]$ & $1.14[0.68-1.4]$ & 0.01 \\
\hline FSH & $4.7[4.2-5.4]$ & $4.7[4-5.4]$ & $5.1[2.4-14.4]$ & 0.59 \\
\hline$\overline{\mathrm{LH}}$ & $6 . .2[4.9-7.3]$ & $6.4[4.3-7.8]$ & $5.3[4.2-12.1]$ & 0.93 \\
\hline Treatment with beta blockers & $37(42 \%)$ & $33(45 \%)$ & $4(31 \%)$ & 0.35 \\
\hline IIEF5 & $14[9-16]$ & $11[9.6-12.4]$ & $24[23.7-24.3]$ & $<0.001$ \\
\hline
\end{tabular}

Data are expressed as medians [95\% confidence interval] or numbers (percentage)

* data missing for 26 patients 
MELD Model for End-stage Liver Disease; TIPS transjugular intrahepatic portosystemic shunt; NASH: non-alcoholic steato-hepatitis; BMI: body mass index; INR: international normalized ratio; PT: prothrombin time 
Table 2: Hepatic encephalopathy and erectile dysfunction: characteristics of the 87 patients

\begin{tabular}{|c|c|c|c|c|}
\hline Evaluation & Overall $(\mathbf{n}=\mathbf{8 7})$ & ED $(\mathbf{n = 7 4})$ & No ED $(\mathbf{n = 1 3})$ & $\mathbf{p}$ \\
\hline MHE & & & & \\
According PHES* & $25(33 \%)$ & $23(30 \%)$ & $2(3 \%)$ & 0.14 \\
According to CFF** & $28(44 \%)$ & $24(37 \%)$ & $4(6 \%)$ & 0.60 \\
\hline CFF & $40[39-41]$ & $40[39-42]$ & $43[39-48]$ & 0.08 \\
\hline NCT-A & $\mathbf{4 8}[\mathbf{4 2 - 5 4}]$ & $\mathbf{5 0}[\mathbf{4 2 - 6 0}]$ & $\mathbf{3 9}[\mathbf{3 0 - 5 2}]$ & $\mathbf{0 . 0 2}$ \\
\hline NCT-B & $\mathbf{1 2 9}[\mathbf{1 0 5 - 1 5 0}]$ & $\mathbf{1 4 2}[\mathbf{1 0 8 - 1 5 5}]$ & $\mathbf{8 3}[\mathbf{5 0 - 1 4 6}]$ & $\mathbf{0 . 0 0 7}$ \\
\hline DST & $\mathbf{3 0}[\mathbf{2 5 - 3 3}]$ & $\mathbf{2 8}[\mathbf{2 2 - 3 2}]$ & $\mathbf{3 7}[\mathbf{2 8 - 4 7}]$ & $\mathbf{0 . 0 5}$ \\
\hline SDT & $70[62-80]$ & $72[64-84]$ & $56[40-88]$ & 0.07 \\
\hline LTT & $\mathbf{1 1 8}[\mathbf{1 0 5 - 1 3 2}]$ & $\mathbf{1 2 3}[\mathbf{1 0 6}-\mathbf{1 3 8}]$ & $\mathbf{1 0 2}[\mathbf{7 4 - 1 2 2}]$ & $\mathbf{0 . 0 2}$ \\
\hline Total PHES & $\mathbf{- 3}[-\mathbf{4 - - 2}]$ & $\mathbf{- 3}[-\mathbf{- 4}-\mathbf{2}]$ & $\mathbf{0}[-\mathbf{4 - 1}]$ & $\mathbf{0 . 0 2}$ \\
\hline
\end{tabular}

Data are expressed as medians [95\% confidence interval] or numbers (percentage)

MHE: minimal hepatic encephalopathy, PHES: Psychometric hepatic encephalopathy test score; CFF: critical flicker frequency; NCT-A: number connecting test A; NCT-B: number connecting test B; DST: digital symbol test; Serial dotting test: SDT; LTT: Line tracing test.

* Data missing for 11 patients

** Data missing for 23 patients 
Table 3: Multivariate analysis of independent factors associated with erectile dysfunction

Model 1

\begin{tabular}{|c|c|c|c|}
\hline Factor & OR & $95 \%$ CI & $\mathrm{p}$ \\
\hline Age & 1.27 & $1.09-1.50$ & 0.002 \\
\hline Child-Pugh score & 3.05 & $1.39-6.70$ & 0.005 \\
\hline PHES & 0.84 & $0.6-1.18$ & 0.33 \\
\hline Testosterone & 1.14 & $0.78-1.70$ & 0.49 \\
\hline
\end{tabular}

PHES: Psychometric hepatic encephalopathy test score

Model 2

\begin{tabular}{|c|c|c|c|}
\hline Factor & OR & $95 \%$ CI & $\mathrm{p}$ \\
\hline Age & 1.17 & $1.05-1.30$ & 0.003 \\
\hline MELD score & 1.19 & $1.01-1.40$ & 0.04 \\
\hline PHES & 0.77 & $0.56-1.06$ & 0.12 \\
\hline Testosterone & 0.98 & $0.70-1.37$ & 0.90 \\
\hline
\end{tabular}

MELD: Model for End-stage Liver Disease

PHES: Psychometric hepatic encephalopathy test score

Figure 1: Flow chart of the 87 patients included in the study.

Figure 2: Scores on the components of the PHES according to the presence of ED. NCT-A, NCT-B, DST and LTT scores were significantly higher in patients with ED.

Figure 3: Correlation between prostatic symptoms and ED. Negative correlations were found between the IIEF5 score and the IPSS ( $\mathrm{r}=-0.2972, \mathrm{p}=0.03)$ and between the IIEF5 score and the IPSS quality of life score $(r=-0.3239, \mathrm{p}=0.002)$.

Supplementary Figure 1:A correlation was found between PHES and IIEF5 questionnaire $(\mathrm{r}=0.2459, \mathrm{p}=0.03)$

Supplementary Table 1: The International Index of Erectile Function (IIEF5) score.

Supplementary Table 2: The International prostate symptom score (IPSS) questionnaire.

Supplementary Table 3: Age-adjusted comparison of patients and healthy controls for known factors of ED 


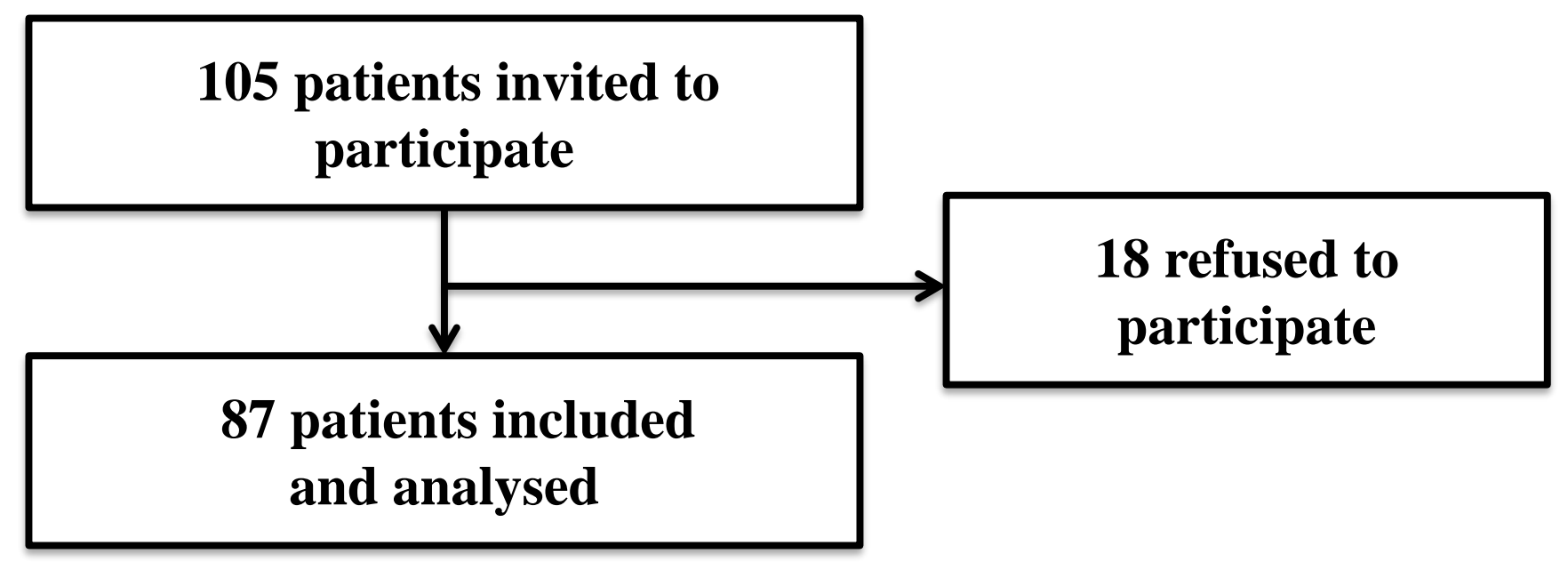


NCT-A

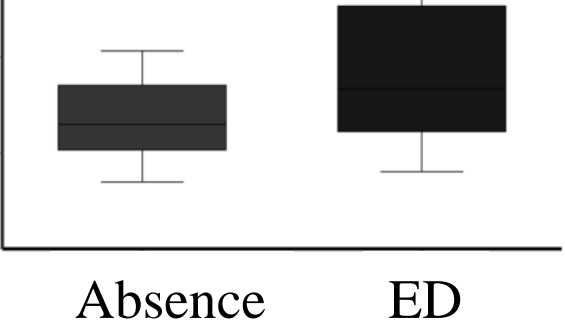

of ED

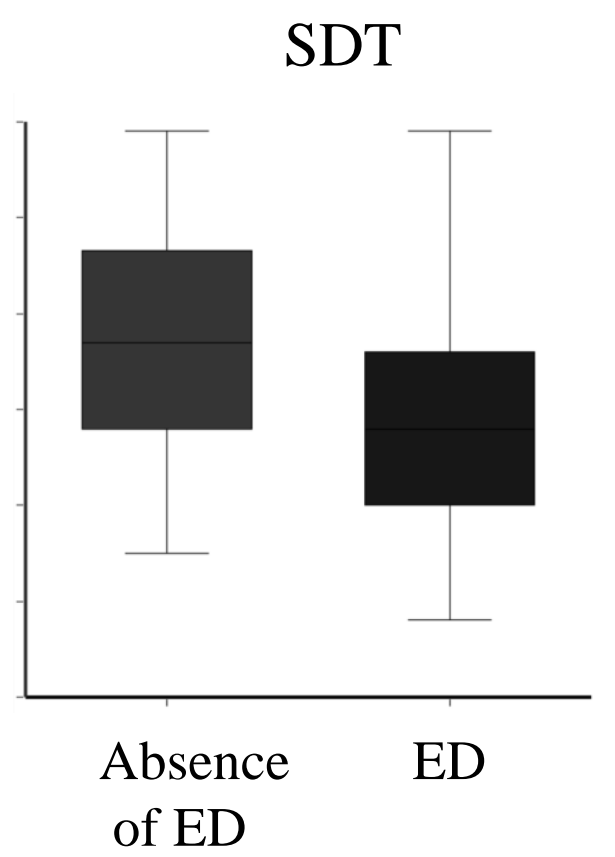

NCT-B

DST

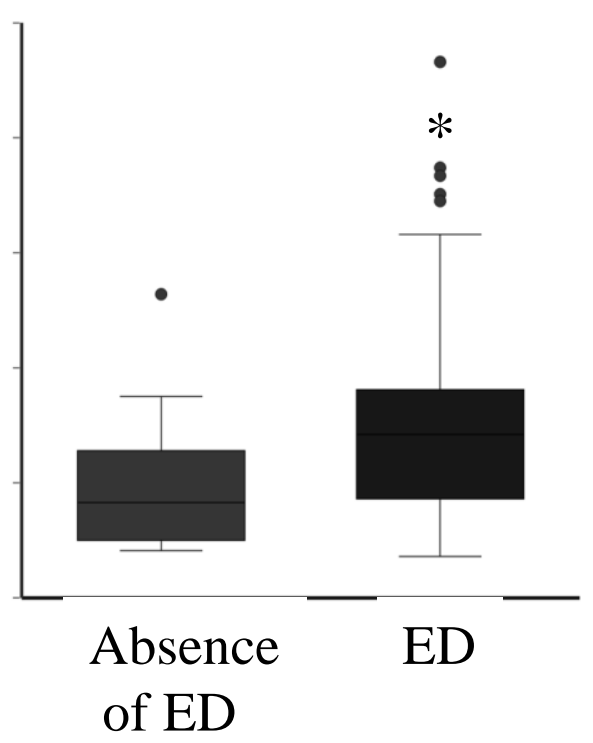

LTT

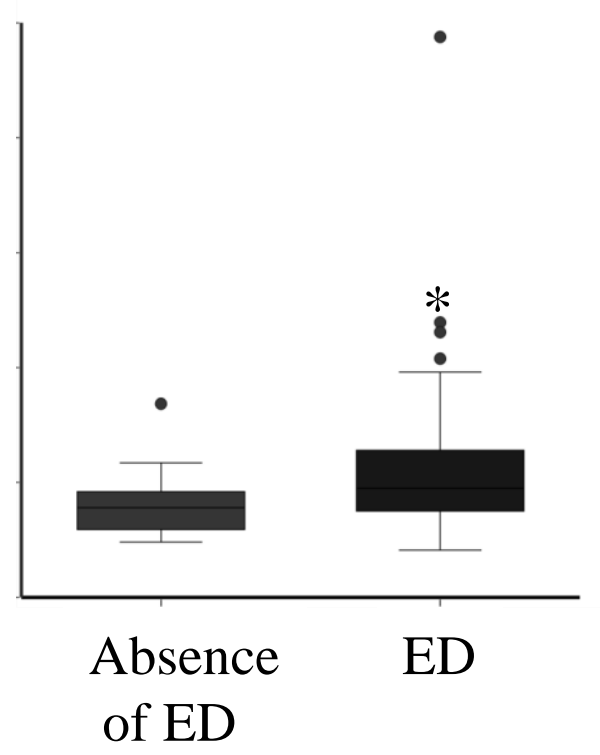

$*: p<0.05$

Figure 2 


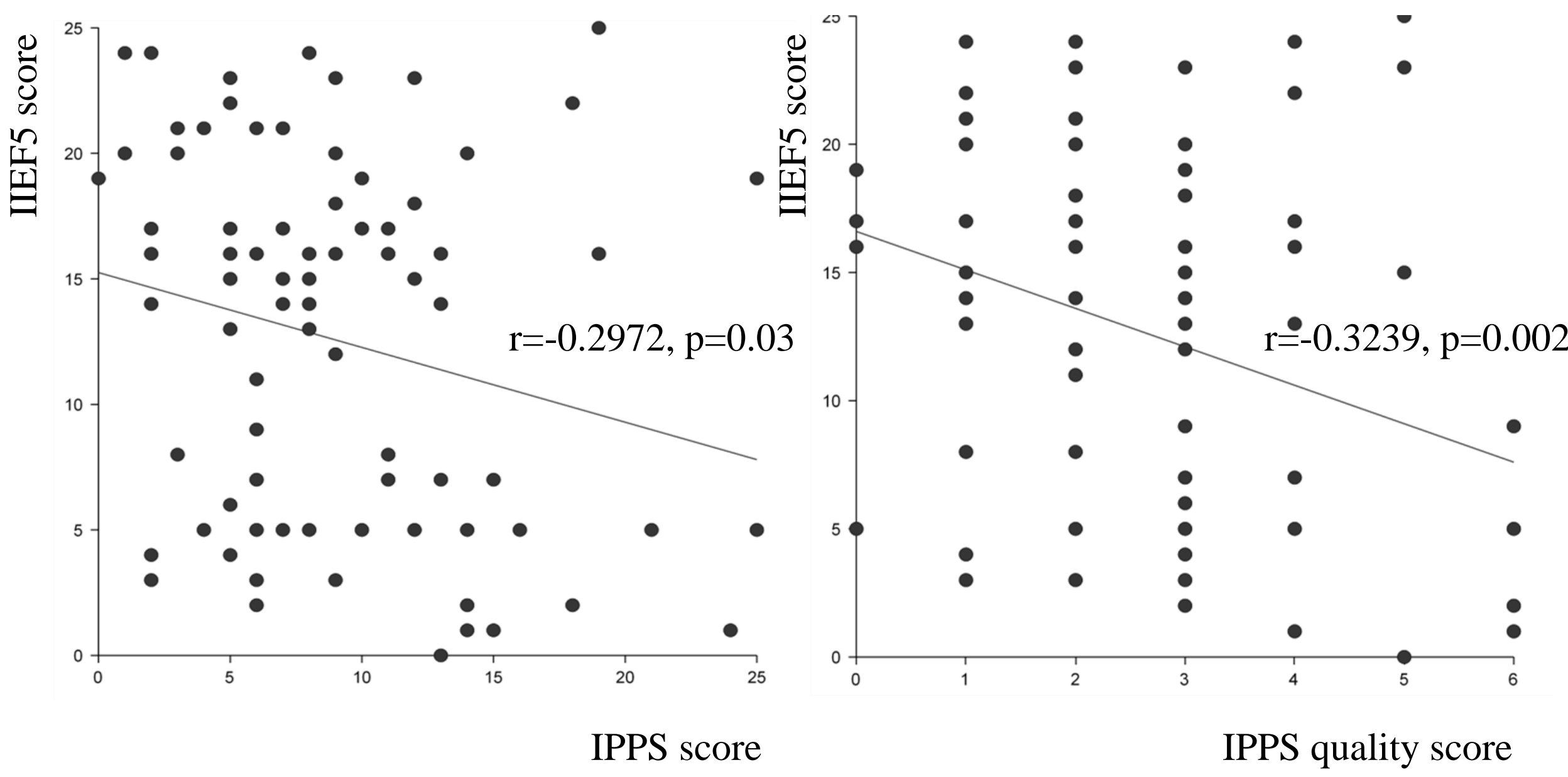

Figure 3 